\title{
Some Observations on Asymmetrical Separation in Thermal Diffusion Columns
}

\author{
M. F. L. MORGADO \\ INSTITUTO SUPERIOR DE ENGENHARIA \\ PORTO, PORTUGAL
}

J. DE D. R. S. PINHEIRO

CENTRO DE QUIMICA PURA E APPLICADA

UNIVERSIDADE DO MINHO

BRAGA. PORTUGAL

T. R. BOTT and M. BOURKIZA

CHEMICAL ENGINEERING DEPARTMENT

UNIVERSITY OF BIRMINGHAM

BIRMINGHAM B15 2TT, UNITED KINGDOM

\begin{abstract}
Data have been obtained in steady-state batch operated thermogravitational separation columns using different binary mixtures to test the theory recently published by Morgado et al. The experimental results confirm that separations by thermal diffusion are asymmetrical except when the initial concentration is 0.5 and that the asymmetry is larger as the initial concentration deviates from 0.5 and as the separation potential increases.
\end{abstract}

\section{INTRODUCTION}

In a recent paper Morgado et al. (1) developed the theory of Furry et al. (2) for nonsymmetrical separations in thermal diffusion columns. The conclusion from the studies was that all separations are generally asymmetric, and that for particular initial concentrations the asymmetry is larger as the separation potential increases. Only when the initial composition of the binary mixture is $0.5 \mathrm{~mol}$ fraction can the separation be regarded as 
symmetrical. The majority of experimental data reported often relate to equimolar test mixtures which from the developed theory ( 1 ) would give symmetrical separation; this can lead to misinterpretation. No recognition of the possibility of nonsymmetrical separation, for instance, was made in the papers of some workers (3-6).

From the theory of Furry et al. (2) for thermogravitational columns in steady-state batch separation, expressions for concentration distribution of the specified component can be derived:

$$
c_{B \infty}=\frac{e^{\lambda c_{o}}-1}{e^{\lambda}-1}
$$

and

$$
c_{T \infty}=\frac{1-e^{-\lambda c_{0}}}{1-e^{-\lambda}}
$$

If the symmetry of separation is defined as an "asymmetry factor" $A_{f}$,

$$
A_{f}=\ln \frac{c_{T \infty}-c_{\mathrm{o}}}{c_{\mathrm{o}}-c_{B \infty}}
$$

where $c_{T \propto}$ refers to the extremity where the specified product accumulates.

By substitution of Eqs. (1) and (2) into Eq. (3):

$$
A_{f}=\ln \frac{\left(e^{\lambda}-1\right)\left(e^{-\lambda c_{0}}-1-c_{\mathrm{o}} e^{-\lambda}+c_{\mathrm{o}}\right)}{\left(e^{-\lambda}-1\right)\left(c_{0} e^{-\lambda}-c_{\mathrm{o}}-e^{\lambda c_{0}}+1\right)}
$$

A symmetrical separation can be defined if

$$
c_{T \infty}-c_{\mathrm{o}}=c_{\mathrm{o}}-c_{B \infty}
$$

i.e., $A_{f}=0$, and the solutions to Eq. (4) are zero when $\lambda=0$ and there is no separation, and $c_{\mathrm{o}}=0.5$.

For each value of the separation potential, the asymmetry of separation increases as the initial concentration is further removed from 0.5 . Furthermore for a given initial concentration, the asymmetry is larger as the separation potential increases. 


\section{EXPERIMENTAL}

Mixtures with different initial concentrations $c_{\mathrm{o}}$ were introduced into two experimental thermogravitational columns and the concentrations at the extremities of the columns measured after steady-state separation had been achieved. Steady-state was assumed to have been reached when variations less than $0.5 \%$ in the concentration of samples taken from ports located at the top and bottom of the respective columns were observed over a period of $2 \mathrm{~h}$.

The dimensions of the two columns are listed in Table 1. Both columns were cooled on one side with water pumped from a thermostatically controlled tank. Column 1 was heated by water pumped from another thermostatically controlled tank whereas Column 2 was electrically heated.

The binary systems investigated in the experimental equipment are listed in Table 2.

Measurements of the refractive index were used to analyze the composition of the liquid samples by using an accurate Abbe refractometer at $25^{\circ} \mathrm{C}$. Calibration curves for each mixture were made by using mixtures of known composition so that sample composition could be directly determined.

The asymmetry factor $A_{f}$ was obtained directly from Eq. (3), and the separation potential $\lambda$ was calculated from

$$
\lambda=\ln \frac{c_{T \infty}\left(1-c_{B \infty}\right)}{c_{B \infty}\left(1-c_{T \infty}\right)}
$$

Theoretical values of $A_{f}$ were obtained from Eq. (4).

The data obtained are shown in Fig. 1 to 4 which are plots of asymmetry factor $A_{f}$ against separation potential $\lambda$ for different initial compositions of the feed mixture. Although there is considerable scatter in the results, it is possible to determine trends which would be expected from the theory (as defined by the line shown on the curves). The asymmetry is larger as the initial concentration is removed from 0.5 and, furthermore, is larger as the separation potential increases.

TABLE 1

\begin{tabular}{ccc}
\hline $\begin{array}{c}\text { Column } \\
\text { no. }\end{array}$ & $\begin{array}{c}\text { Length } \\
(\mathrm{m})\end{array}$ & $\begin{array}{c}\text { Annulus width, } \\
\mathrm{m} \times 10^{4}\end{array}$ \\
\hline 1 & 0.83 & 5.00 \\
2 & 1.27 & 3.09 \\
\hline
\end{tabular}


TABLE 2

\begin{tabular}{|c|c|c|}
\hline $\begin{array}{c}\text { Column } \\
\text { no. }\end{array}$ & Binary mixture & $\begin{array}{l}\text { Symbol used } \\
\text { in Figs. 1-4 }\end{array}$ \\
\hline \multirow[t]{2}{*}{1} & $n$-Heptane, toluene & $\odot$ \\
\hline & $n$-Heptane, methylcyclohexane & $\nabla$ \\
\hline \multirow[t]{7}{*}{2} & Cyclohex anol, $n$-hexanol & - \\
\hline & Benzyl alcohol, $n$-octanol & $\Delta$ \\
\hline & Acetophenone, $n$-nonane & $x$ \\
\hline & $m$-Xylene, isooctane & 曰 \\
\hline & Ethylbenzene, $n$-octane & $\varnothing$ \\
\hline & $n$-Butanol, 1,1,2,3-tetrachloroethylene & + \\
\hline & $n$-Hexanol, benzyl alcohol & - \\
\hline
\end{tabular}

\section{SYMBOLS}

$A_{f} \quad$ asymmetry factor

$c_{\mathrm{o}} \quad$ initial concentration

$c_{B \infty} \quad$ concentration in the bottom of the column in steady-state

$c_{T \infty} \quad$ concentration in the top of the column in steady-state

$\lambda \quad$ separation potential 


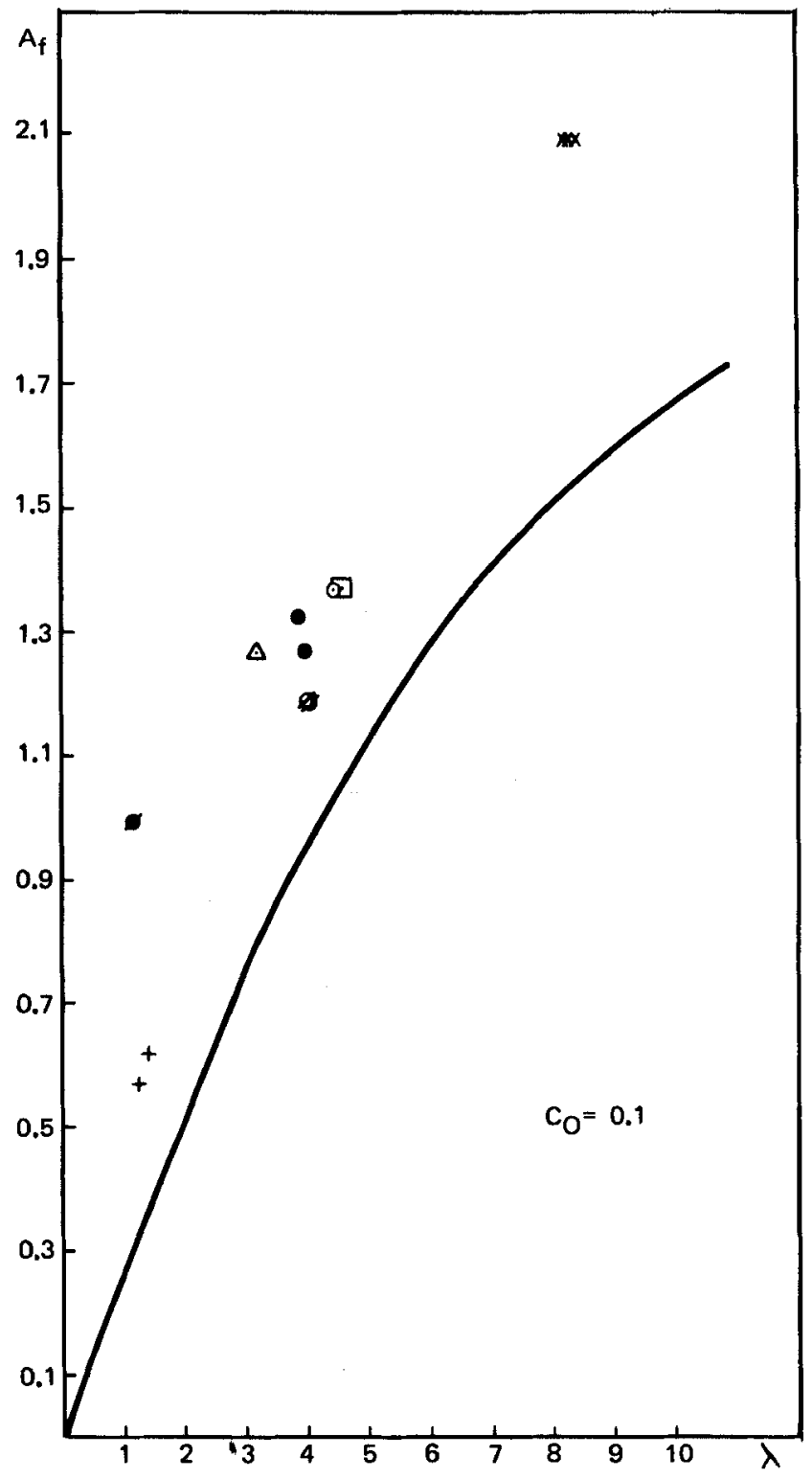

FIG. 1. Asymmetry factor vs separation potential for initial concentration $0.1 \mathrm{~mol}$ fraction. 


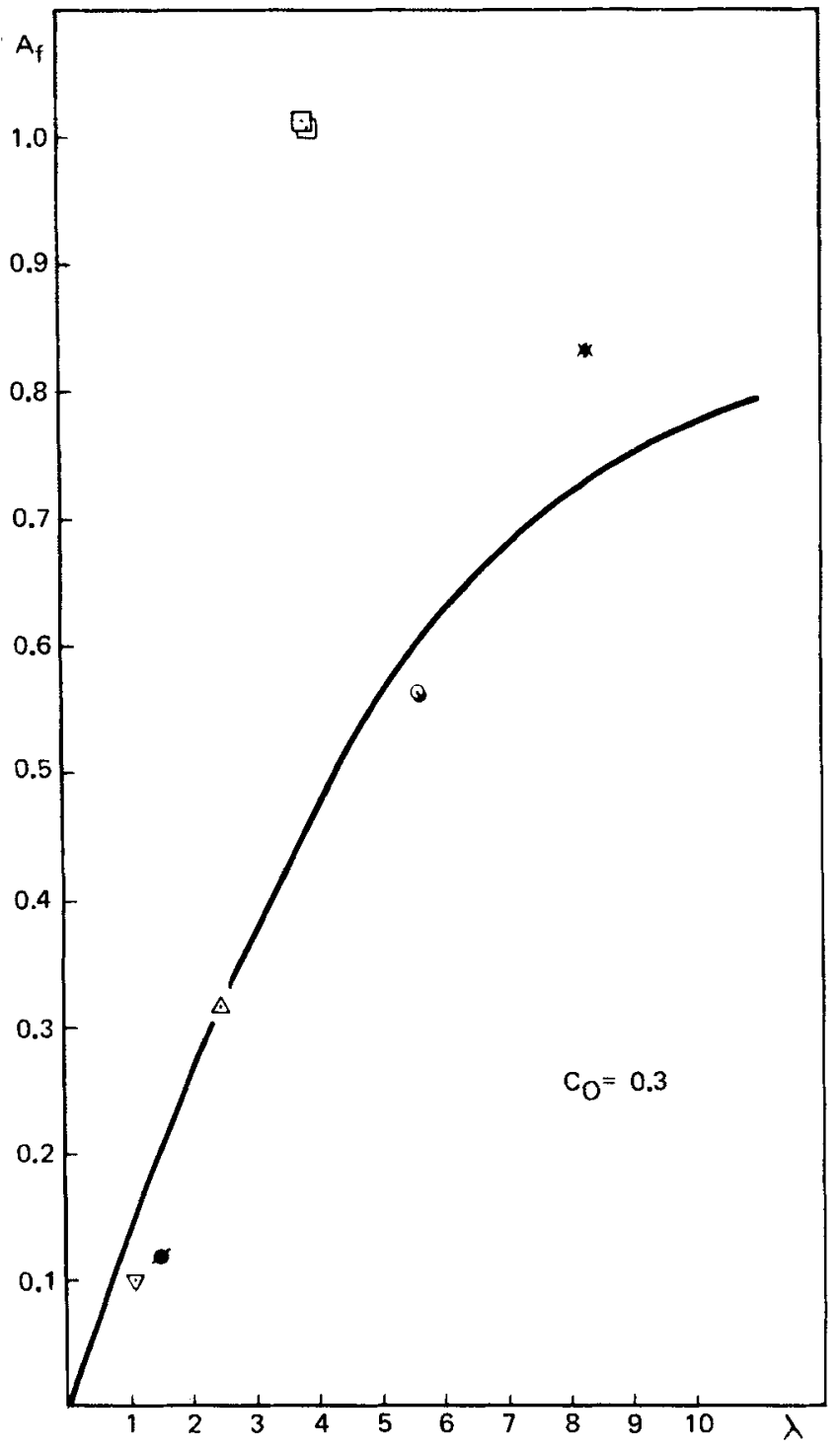

FIG. 2. Asymmetry factor vs separation potential for initial concentration $0.3 \mathrm{~mol}$ fraction. 


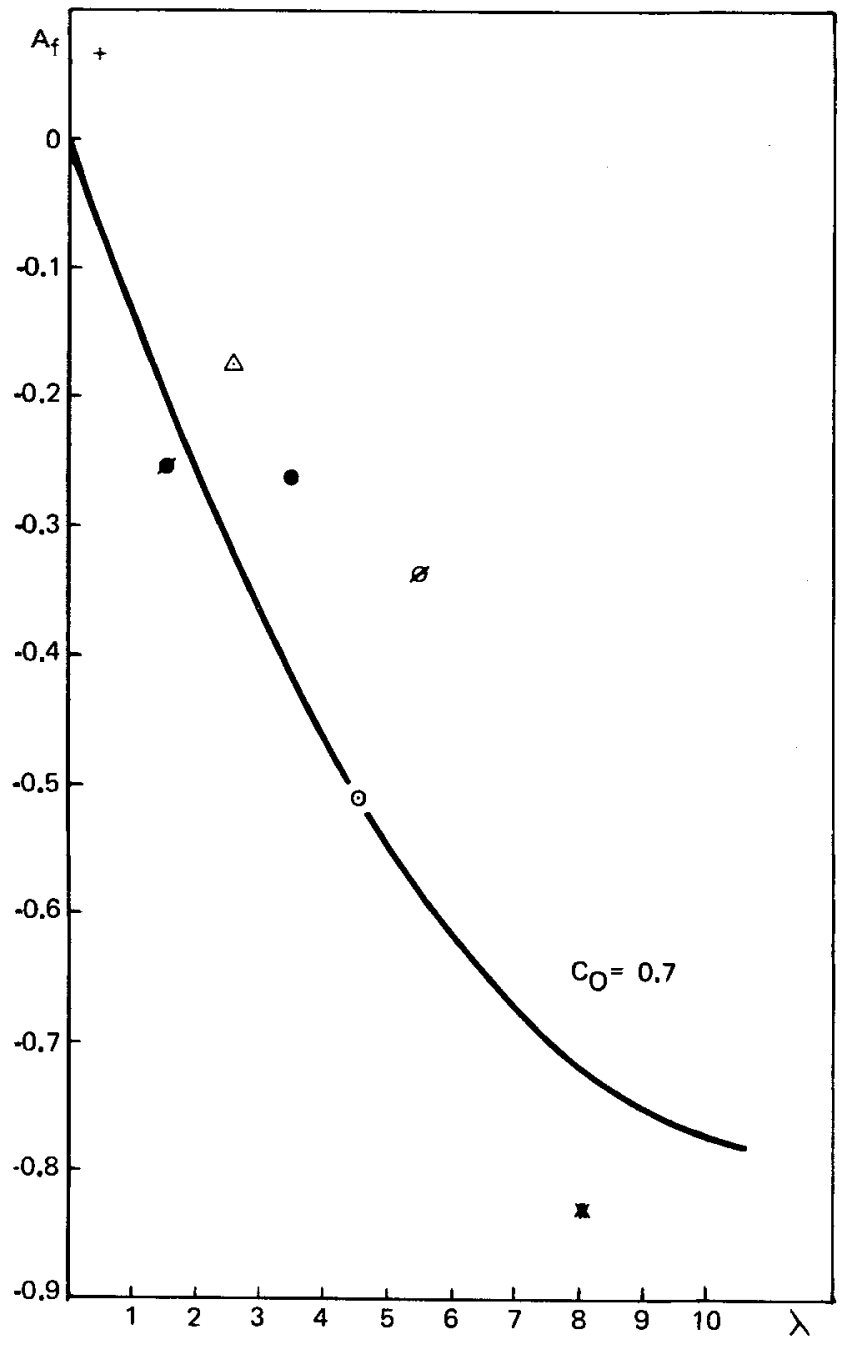

FIG. 3. Asymmetry factor vs separation potential for initial concentration $0.7 \mathrm{~mol}$ fraction. 


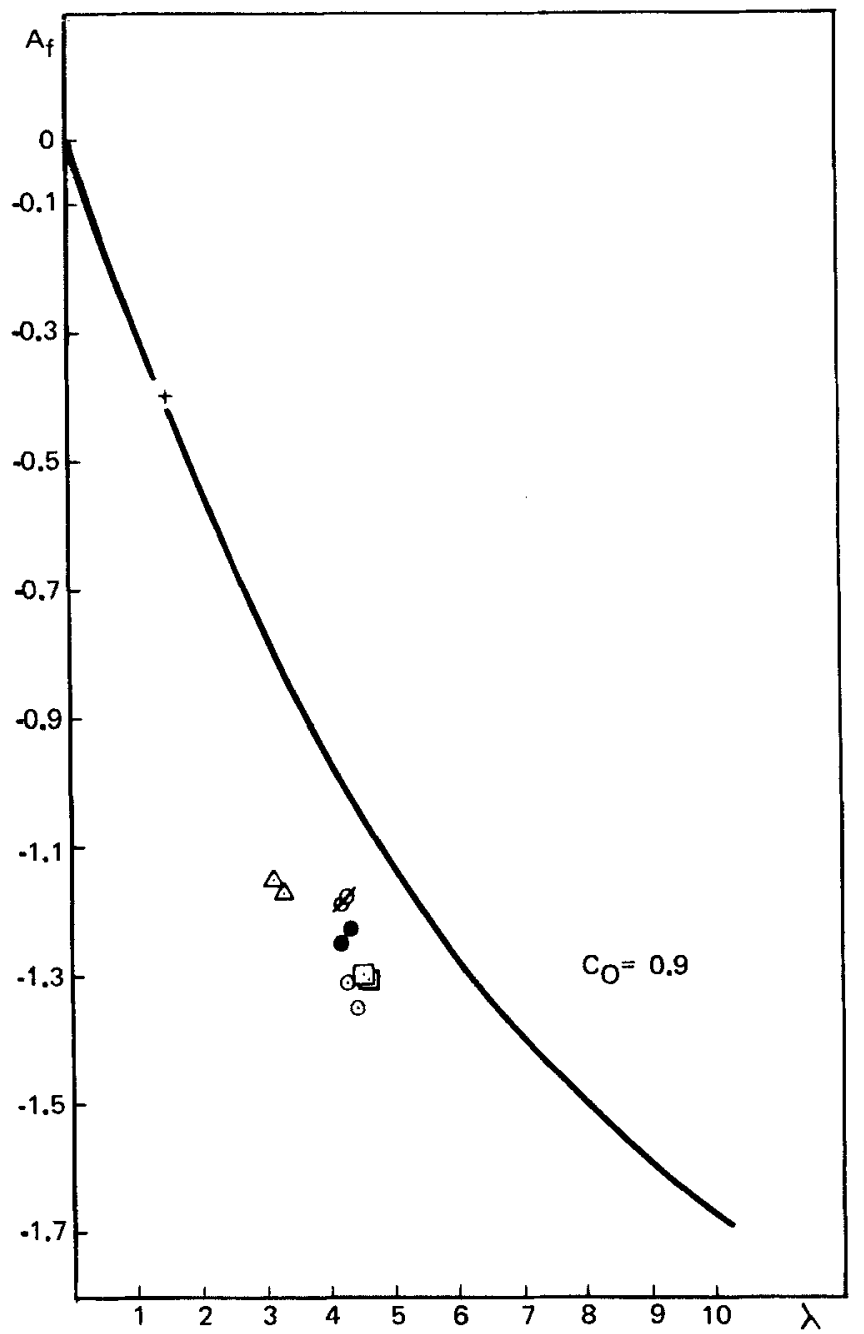

FIG. 4. Asymmetry factor vs separation potential for initial concentration 0.9 mol fraction. 


\section{Acknowledgment}

The authors would like to acknowledge, with thanks, the grant awarded by NATO (Scientific Affairs Division) which enabled some of this work to be carried out.

\section{REFERENCES}

1. M. F. Morgado, J. D. R. Pinheiro, J. J. B. Romero, and T. R. Bott, Sep. Sci. Technol., 16(8), 897 (1981).

2. W. H. Furry, R. C. Jones, and L. Onsager, Phys. Rev. 35, 1083 (1939).

3. F. H. Horne, and R. J. Bearman, J. Chem. Phys., 37, 2840 (1962).

4. T. C. Ruppel and J. Coull, Ind. Eng. Chem., Fundam., 3, 368 (1964).

5. D. J. Hoffman, and A. H. Emery, AIChE J., 9, 653 (1963).

6. Powers, J. E., in New Chemical Engineering Separation Techniques (H. M. Schoen, ed.), Wiley-Interscience, New York, 1962.

Received by editor July 26, 1982

Revised November 2, 1982 